\title{
A INVOCAÇÃo DOS RANCORES: ALIENI(ILI)SMO E (IN)TRANSCENDÊNCIA NA PERTURBAÇÃO DE THOMAS BERNHARD
}

\author{
Ravel Giordano Paz \\ Universidade Estadual do Mato Grosso do Sul - UEMS \\ ravelgp@yahoo.com.br
}

Resumo: $\mathrm{O}$ artigo intenta uma leitura progressiva, quase linear, do romance Perturbação (Verstörung), de Thomas Bernhard, buscando demonstrar sua irredutibilidade significacional à negatividade existencial e ao transtorno psíquico, quando não o niilismo, que emanam de seus personagens principais (incluindo o narrador), ou ainda ao conflito entre tradição e modernidade que o emoldura historicamente: para além de tudo isso, uma acirrada e, a seu modo, apaixonada dialética de mesmidade e transcendência - em cujo cerne localizamos os topoisentimentos fundamentais da herança e da propriedade - move as relações familiares e sociais e os jogos enunciativos entre as vozes-abismos que o povoam.

Palavras-chave: Thomas Bernhard; romance contemporâneo; literaturas de língua alemã.

Abstract: This article intents a progressive and almost linear reading of the novel Perturbação (Verstörung; in English, Gargoyles), by Thomas Bernhard, seeking to demonstrate its significational irreducibility to existential negativity and mental disorder, or even nihilism, which emanate from its main characters (including the narrator), and also the conflict between tradition and modernity that historically framed it. More than that, a strained and, in its way, passionate dialectic of sameness and transcendence - in whose heartwood we found the fundamental motif-feelings of inheritance and property - move the family and social relationships and the games between enunciative voices-abysses that inhabit this novel.

Keywords: Thomas Bernhard; contemporary novel; German-language literature.

\section{A paixão negadora e os abismos perturbados}

Marcada por uma negatividade tão evidentemente hegemônica - mas também, portanto, não exclusiva -, a obra de Thomas Bernhard parece, a princípio, o avesso do que se possa conceber como uma literatura de inspiração ou entusiasmo. Quem, no entanto, conhece a prosa bernhardiana sabe de seu vigor intelectual, linguístico, escritural ou como quer que se denomine o que se sente de vivo e pulsante nela, para além, mesmo, em certo sentido, de seu vigor crítico e polêmico, embora quase sempre indissociável dele. Bernhard foi, certamente, um dos autores da segunda metade do século XX que mergulhou de forma mais intensa nas contradições de seu tempo e seu mundo, em larga medida, aliás, nosso tempo-mundo. Intensa e, em certo sentido, apaixonada, porquanto um labor inspirado emana de sua escrita; uma escrita, portanto, com seu quê de poética, inclusive no sentido aurático a que, mesmo após as tormentas de todas as vanguardas, nunca deixou totalmente de se vincular a essa palavra. Sem pejo, entretanto, de sua força negativa: se é o caso de designar algo com a radicalidade máxima ou o 'verdadeiro tema' de Bernhard, talvez se deva remeter 
ao substantivo que intitula seu último e, para muitos, principal romance: Extinção, de 1986. Mas já em Perturbação, de 1967, ${ }^{1}$ os laivos de positividade só têm força e interesse no âmbito de situações paradoxais. Em suma, é sempre numa dialética onde a negatividade é um dado fulcral que se entrevê o que se pode denominar o entusiasmo secreto da prosa de Bernhard: a ambígua e dolorosa prática de uma devastação que busca ali mesmo, entre as ruínas, algo precioso: uma centelha do que se costuma chamar o humano. De fato, sob a casca de violência física e moral dos enredos de Bernhard, percebe-se a transparência de um humanismo. Negar, entretanto, que também a negatividade habita esse 'fundo' seria negar não só a complexidade como a radicalidade paradoxal desse humanismo: o fato de que justamente de um ágon consigo mesmo ele extrai, para além do negativismo, a força de uma paixão negadora. A prosa de Bernhard guarda algo, pode-se dizer, de um heroísmo extremo - e dos extremos.

É, por sinal, justamente a defrontação com um pavor extremo, conquanto 'abstrato', que anuncia, em epígrafe, a narrativa de que tratamos: "O silêncio eterno desses espaços infinitos me apavora". ${ }^{2}$ Uma invocação dos abismos que é também, sem dúvida, a reivindicação de uma atitude inspirada: afinal, a fonte desse pavor guarda algo da concepção de Pascal, o autor da frase, da infinitude e do incomensurável como atributos de Deus ${ }^{3}$. Não por acaso, Perturbação é uma narrativa em cujo centro ou extremo - seja como for, um centro-extremo desmedidamente grande ${ }^{4}$ - descobrimos cada vez mais firmemente instalado o tema da loucura, particularmente na forma de um 'excentrismo' que, privilégio ou não dos ricos - conforme a velha anedota -, possui seu quê de brilhante. Mas é claro que a loucura, em Perturbação, confina muito mais - pelo menos muito mais explicitamente - com o negativismo moral, quando não com o niilismo, que com qualquer outra coisa, além de ser submetida a um tipo de exame, quando menos de exposição, que traz muito mais as marcas de um discurso

\footnotetext{
1 Tradução brasileira de H. P. Welper e J. L. de Melo (Rocco, 1999), cotejada com a edição em alemão da Suhrkamp (6a ed., 1990), à qual recorreremos quando necessário. De um modo geral, Welper e Melo seguem de perto o original, apesar de algumas opções inexplicáveis, como a tradução de "Verstörungen" por "transtornos" (e não "perturbações") e "katastrophalen" por "desastroso" (e não "catastrófico"), ambas à p. 153 (133, no original), sendo que a primeira palavra obviamente remete ao título e a segunda é de importância igualmente marcada no romance: pouco adiante (p. 159 na tradução, 137 no original), por exemplo, "catástrofe" ("Katastrophe”) aparece três vezes no espaço de quatro linhas.

2 Bernhard. Perturbação, p. XI.

3 "Segundo Pascal, Deus se encontra a uma distância muito mais infinita do que aquela que nos separa da natureza das coisas. Deus não tem extensão nem limites, assim, não possuímos uma medida que nos permita conhecê-lo." (Pinto. A noção de perspectivismo na filosofia de Blaise Pascal, p. 144.)

4 Ocupando cerca de um terço da narrativa, o semimonólogo do Príncipe Saurau - o "centro ou extremo" de que falamos - é uma espécie de segunda e última parte do romance, e a única que recebe um título ("O príncipe"). Espacialmente, trata-se do fim de um percurso - o trajeto do narrador e seu pai, que, em termos de enredo, constitui o núcleo da narrativa, no seu todo emoldurada pela saída e a volta de casa -, mas também de um lugar de convergência das tensões que se acumulam até aí. Naturalmente, todo esse jogo de simetrias e assimetrias é importante para o efeito de vertigem buscado por Bernhard.
} 
racional que propriamente alucinado, muito embora tudo nos convide a discutir o estatuto dessa 'razão'. Até porque esse discurso analítico-expositivo não pode se manter imune ao fluxo - o decurso - dos discursos não raro maníacos que afinal constituem sua substância, ele próprio, portanto, configurando-se como um discurso - um ser-em-curso - perturbado.

Assim, o marcado intelectualismo da prosa de Bernhard é um componente que se autodesconstrói, ou melhor, que, muito embora sem abdicar de si mesmo - do sentimento de seu valor -, presta-se ele próprio à desconstrução das bases (culturais, cognitivas, sociais) que evidencia compartilhar com os discursos-subjetividades de que se alimenta. Daí loucura, niilismo e alienação se emaranharem, em Perturbação, num complexo do qual o sentimento ou, quando menos, a demanda de alguma transcendência é indissociável. A narração em primeira pessoa, com a relação de contágio - ou melhor, a tortuosa dialética de apartamento e entranhamento (e entranhamento/estranhamento) - que ela cria entre seus 'objetos', é, nesse sentido, muito mais do que uma estratégia narrativa: a colcha de retalhos discursiva, com seu tortuoso dialogismo, emana também a força de invocações das alteridades abissais, das vozes-abismos, tão mais sensíveis porquanto filtradas pelos rancores que as desentranham. ${ }^{5}$ Reconhecer, para além dos conflitos sociais e mesmo psicológicos, o dialogismo agonístico de Perturbação é fundamental para sondarmos não só o peso dos conflitos na prosa de Bernhard como, quiçá, alguma aspiração que ela queira nos legar.

\section{Um médico e seus monstros}

No desenho geral de seu enredo, Perturbação consiste na narração dos eventos, o mais das vezes discursivos, transcorridos ao longo de um dia de visitas domiciliais de um médico interiorano, em fins de setembro, numa inóspita região austríaca. O narrador é o filho do médico, um jovem universitário que, pela primeira vez e aparentemente meio por acaso, o acompanha nessas visitas: de volta, ainda de manhã, de duas consultas em plena madrugada, numa das quais assistira à morte do paciente, o pai convida o filho para ver um "fenômeno da natureza", um castanheiro em flor em pleno outono austríaco, às margens do rio Ache; quase à saída do passeio, no entanto, um taberneiro de um povoado vizinho bate à porta pedindo que o médico o acompanhe. Sua esposa, atendendo de madrugada alguns mineiros que, bêbados, se hostilizavam na taverna, recebera de um deles, "sem mais nem menos, um soco na cabeça e no mesmo instante caíra no chão sem sentidos”. Esse

\footnotetext{
5 A abundância de recursos de diferenciação das instâncias discursivas na narração, que constataremos em várias citações, também indicia a proximidade problemática, ou o entrelaçamento tenso, das vozes.
} 
episódio vagamente policialesco, e que pontuará todo o romance, pode ser visto como a perturbação inaugural da narrativa - a partir da visita inesperada, "não se falou mais no castanheiro em flor e passamos a ouvir as coisas mais inquietantes sobre a mulher do taberneiro" $"$, responsável por investi-la desde cedo do élan sinistro que será sua sombra quase perene, além de servir como pasto para suas primeiras ruminações discursivas de negatividade extrema.

É ao próprio médico, nesse caso, que cumpre dissecar, em tom analítico mas não menos condenatório, a condição social e, sobretudo, moral da realidade que quer dar a conhecer ao filho. Sua longa preleção parte da "monstruosa falta de delicadeza por parte dos taberneiros" - que insistiam em manter seus bares "abertos até altas horas da noite porque só pensavam em seus negócios", mas iam "para a cama cedo porque durante todo o dia se tinham extenuado em seus matadouros, seus currais, suas lavouras", deixando suas mulheres entregues "a um mundo de homens que, com o consumo crescente de álcool até a madrugada, se reprimiam cada vez menos na expressão de sua brutalidade" - e termina afirmando a condição de criminalidade de todos os habitantes pobres da região rural, pois "No campo a brutalidade, como a violência, era a base de tudo", e o próprio taberneiro "era um delinquente e um criminoso nato. Tudo nele e dentro dele era violento e criminoso".7

Mas este, naturalmente, é um típico feitiço contra o feiticeiro. Para além de sua função retórica - ou ainda, talvez, de marca de oralidade -, os elementos redundantes acima ("brutalidade" e "violência"; "delinqüente" e "criminoso"; "nele e dentro dele"; "violento e criminoso") evidenciam as marcas de uma violência linguística e, portanto, psíquica ou psicossocial na própria fala do médico, e, ainda, na fala que fala dela, ou seja, a do narrador, como atesta o uso que ele faz dos itálicos. Por exemplo: após notar que seu pai, já à mesa do café na casa de um amigo advogado, também havia falado da visita que fizera de madrugada ao filho de um mineiro, e na qual fora tratado cordialmente, o narrador indica que ele, seu pai, "depois de se referir mais uma vez ao menino e suas queimaduras, e de ter imitado seu modo de falar, voltou a mencionar o taberneiro". 8 O fato desse sarcasmo ser exposto numa construção sintaticamente subordinada, sem deixar de ser sublinbado - em suma, essa inóspita 'sutileza' do narrador -, é parte de uma rede discursiva onde pesam não só os ditos e reditos mas também os não ditos e entreditos. Nesse episódio mesmo, o médico leva o filho à casa do advogado esperando "que seu amigo nos oferecesse um bom

\footnotetext{
${ }^{6}$ Bernhard. Perturbação, p. 3.

${ }^{7}$ Bernhard. Perturbação, p. 7-11; grifos do autor.

${ }^{8}$ Bernhard. Perturbação, p. 12-13; grifos do autor.
} 
café da manhã"; e, de fato, o narrador afirma que esse café "foi o mais farto que já tomei", registrando ainda que "podia ver, da minha cadeira, a rua e observar o que nela se passava". ${ }^{9}$ Mas não saberemos, absolutamente, o que se passava na rua: logo em seguida o narrador introduz a expressão "falamos" para indicar o início da conversa que, na verdade, é tão somente a preleção do pai. Nenhuma fala é atribuída a si mesmo, narrador, ou ao “amigo advogado", personagem do qual não temos sequer uma descrição, comparecendo apenas como depositário da discursividade rancorosa do médico e doador do farto desjejum, bem como da presença ao que tudo indica agradável de sua "jovem mulher"10, que conduz os visitantes à mesa da qual, entretanto, não sabemos se ela tomou parte ou não. No âmbito de uma prosa que em outros momentos se aferra a detalhes mínimos, essa pequena rede de silenciamentos só pode ter a função de marcar a figura do médico com o selo de uma morbidez egoísta, o que sugere incluí-lo - mas também ao narrador, que se compraz em forjar essa marca - no cerne daquela evidência, que ele havia afirmado pouco antes, "de que tudo era doentio e triste", aliás, como se apressa a corrigir o narrador, "realmente doentio e triste" ${ }^{11}$

Em suma, se Perturbação fosse um conto, reduzindo-se a esses episódios iniciais, seria uma condensação do negativismo opressor de Bernhard, com o qual até agora confina o horizonte do romance. Não é o caso, e o próprio negativismo bernhardiano comporta variações importantes ao longo da narrativa, mas a estrutura circular ou especular desses primeiros episódios marca de alguma forma os demais, culminando na espécie de sintese extrema dos topoi-sentimentos em jogo desde o início que é a longa fala do príncipe Saurau.

Dos pacientes visitados daí em diante pelo médico, pelo menos dois guardam relações especulares explícitas com o príncipe. O primeiro é "um certo Bloch, dono de uma imobiliária", judeu ilustrado de quem o médico diz que "vivia voluntariamente, por apego a seus negócios, no meio de uma embrutecida sociedade montanhesa que, por natureza, lhe era hostil”, e em cuja casa "se faziam 'autópsias da natureza' e também 'do mundo e sua história', se cultivavam 'as ciências políticas comparadas, a história natural aplicada e a história da literatura', e se era impiedoso com a sociedade e não menos com o Estado". ${ }^{12}$ Embora deixe entrever certa distância irônica em relação à usura e mesmo à condição de judeu do negociante, o médico considera Bloch (e afirma isso diante do filho) "a única pessoa com quem podia conversar sem que isso nunca lhe fosse penoso, e também a única em quem

\footnotetext{
${ }^{9}$ Bernhard. Perturbação, p. 11.

${ }^{10}$ Bernhard. Perturbação, p. 10.

11 Bernhard. Perturbação, p. 10; grifos do autor.

12 Bernhard. Perturbação, p. 19-20.
} 
confiava plenamente"13; o que certamente se liga à concep̧̧ão de vida que ele reconhece no amigo:

\begin{abstract}
Meu pai disse que Bloch dominava a arte de considerar a vida um mecanismo cujas funções mais importantes eram fáceis de compreender, um mecanismo que, segundo suas necessidades, podia fazer funcionar num ritmo mais acelerado ou mais lento, porém sempre útil e, portanto, suportável, e se tinha esforçado sempre por iniciar sua família nessa arte, que lhe agradava. ${ }^{14}$
\end{abstract}

Em suma, Bloch é uma espécie de modelo de racionalidade ao mesmo tempo instrumental e 'filosófica' para o médico. Mas é também o primeiro da pequena sequência de personagens cujas cefaleias e insônias crescentes parecem de alguma forma se ligar a práticas e/ou sentimentos de devastação. Pelo menos é de entremeio com o pedido de um sonífero mais forte que ele fala sobre a aquisição que acabara de realizar, e graças à qual um lugar que há "apenas oito dias era campo" tornara-se "um terreno edificável, que ia dividir em mais de cem lotes", pois "dessa forma poderia negociá-lo rapidamente". ${ }^{15}$

Mais adiante, uma racionalidade semelhante à de Bloch se encarna de forma francamente patológica em outro personagem: outro 'livre-pensador' capitalista, cujas propriedades "se espalhavam pelo mundo inteiro" 16 , e que o narrador nos apresenta apenas como "um industrial mais ou menos insano cujo nome esqueci" ${ }^{17}$. Primeiro caso explícito de perturbação mental na narrativa, a obsessão por um obscuro "trabalho literário sobre um tema plenamente filosófico" 18 desse personagem o leva não só a evitar o contato direto com quaisquer pessoas afora o médico e a esposa (e meia irmã, um pouco na lógica da mesmidade, aliás, da mesma idade do casamento de Bloch), como a buscar o completo isolamento sensorial em relação ao mundo. O que determina uma, digamos, empresa que, na economia simbólica do romance, pode ser vista como a primeira de uma assombrosa sequência de imagens de extermínio que a partir daí o costuram: a ordem de mandar "matar toda a caça" de seus bosques particulares: “'Agora não ouço nada quando abro as janelas do corredor', disse o industrial, 'nada. É fantástico.” Graças a esse vazio, “era possível 'realizar um imenso cosmos de ideias", ${ }^{19}$ que no final, entretanto, talvez se resumisse a "um único pensamento". ${ }^{20} \mathrm{O}$ projeto literário-filosófico do personagem também determina sua recusa, declarada e reiterada, a conhecer o filho do médico (que escuta a conversa atrás da

\footnotetext{
${ }^{13}$ Bernhard. Perturbação, p. 23; grifos do autor.

${ }^{14}$ Bernhard. Perturbação, p. 22-23.

15 Bernhard. Perturbação, p. 22.

${ }^{16}$ Bernhard. Perturbação, p. 47.

${ }^{17}$ Bernhard. Perturbação, p. 43.

18 Bernhard. Perturbação, p. 45.

${ }^{19}$ Bernhard. Perturbação, p. 53.

${ }^{20}$ Bernhard. Perturbação, p. 47.
} 
porta), assim como qualquer nova pessoa: “'Não', tornou a dizer o industrial, 'não gostaria de receber seu filho, não gostaria de conhecê-lo. Se de repente me aparece alguém novo pode me destruir tudo. Tudo". ${ }^{21}$ Esse manifesto pavor do outro e do novo, do que quer que perturbe um existente em tese já quase dominado, é talvez a primeira inserção significativa, e como as demais não nomeada, do tema do niilismo ou, talvez mais propriamente, da ânsia do nada em Perturbação: "Como todos os cômodos da casa estão completamente vazios, não posso tropeçar com nada na escuridão que nela reina". ${ }^{22}$ Vazio, o reino da escuridão se torna, um pouco como a vida de Bloch, suportável.

Mas é com o príncipe Saurau que "o industrial” guarda as relações mais fortes. $\mathrm{Na}$ verdade, sua configuração como uma espécie de cópia menor dele é tão marcada, por via da riqueza, da loucura e das ambições intelectuais ${ }^{23}$, que não é estranho que seu nome tenha se apagado ao fim desse longo dia. De fato, isso explica esse "esquecimento", numa narração onde detalhes mínimos são sustentados e sublinhados o tempo todo: como a própria semelhança, trata-se de um dado que reforça a estrutura circular e, com ela, os topoi do estranho-familiar e da alteridade como mesmidade no romance.

De certa forma, também a personagem que conhecemos antes do industrial se insere nessa cadeia, embora sobretudo por explicitar a desordem subjacente à ordem ansiada pelos outros. Habitante de uma casa onde as "irregularidades do pomar eram suspeitas e indicavam pessoas de ritmo vital perturbado", e de um "quarto de doente" onde a "roupa íntima (...) cheirava à doença mortal a que já se entregara sem resistência”, ${ }^{24}$ a Sra. Ebenhön se vale da presença do médico (e do narrador) para falar de suas amarguras familiares. Do suicídio, naquela mesma casa, do irmão mais novo que assassinara a noiva à debilidade moral e intelectual do filho, "um 'monstro" cujas roupas exalavam "um horrível cheiro de cadáver" devido ao curtume onde trabalhava e cuja mulher devotava à sogra "um ódio cada vez mais profundo", passando pelo comportamento supostamente acintoso dos netos pequenos, ${ }^{25}$ a morbidez e os rancores povoam a fala da Sra. Ebenhön, assim como povoarão a do príncipe Saurau.

Como, afinal, esses círculos viciosos povoam o romance. $\mathrm{O}$ apreço do médico por Bloch, por exemplo, também serve de mote para outra de suas preleções, agora contra os antigos colegas de universidade, resignados "a seu monótono destino de médicos, de uma

\footnotetext{
${ }^{21}$ Bernhard. Perturbação, p. 54.

22 Bernhard. Perturbação, p. 54.

${ }^{23}$ E a leitura de jornais velhos, no seu caso "com pelo menos um mês de atraso". (Bernhard. Perturbação, p. 47.)

24 Bernhard. Perturbação, p. 26.

${ }^{25}$ Bernhard. Perturbação, p. 30-33.
} 
forma que durante anos, depois de acabar seus estudos, lhe causara pena mas que agora só lhe inspirava repulsa”. Ele mesmo, porém, partilha a condição prática e moral desses "amigos perdidos, espalhados por toda aquela região hipócrita, exilados em profundos vales sem sol, em cidadezinhas e abúlicos povoados e lugarejos”, antes decididos a "pesquisar e lutar por uma sociedade basicamente enferma" e agora "dedicados à estafa curativa". ${ }^{26}$ Enfim, tudo no romance parece estar íntima e maleficamente implicado entre si.

Mas a cena ou episódio que condensa de forma mais plástica o élan sinistro que envolve a narrativa se dá no caminho que conduz a Hochgobernitz (o castelo do príncipe); mais exatamente em um moinho localizado "no fundo de um despenhadeiro escuro" 27 , propriedade da família Fochler antes pertencente aos Saurau. Ao invés de acompanhar a consulta médica, o narrador se dirige, por sugestão do pai, ao fundo do moinho, onde há uma enorme gaiola de aves exóticas que ele já conhecia, mas que o espanta por estar semideserta e pelos pássaros restantes apavorarem-se à sua chegada. Pouco adiante, ele se deparará com outros pássaros sobre uma mesa, mortos e cheirando a putrefação. Os detalhes dessa outra história de cunho fortemente simbólico, mas nem por isso menos realista, são expostos ao longo de doze páginas: conforme conta um dos filhos do moleiro, os pássaros pertenciam a um velho tio seu, que se dedicava inteira e amorosamente a eles, e desde sua morte, há três semanas, haviam iniciado uma gritaria incessante que transtornava os moradores do moinho. Finalmente - e, segundo o médico, motivado sobretudo pela angústia de um velho cão doméstico -, o velho Fochler ordenara o extermínio das aves, que os filhos e mais um trabalhador turco executavam manualmente, quebrando seus pescoços de modo a não danificar sua valiosa plumagem, sendo que no início esse ato era realizado diante delas, a princípio apavoradas e depois sombriamente emudecidas. Semelhante (ou inverso) condicionamento se manifesta no automatismo do jovem Fochler, que conta a história enquanto repete o abrupto gesto usado para matar os pássaros. ${ }^{28}$

No âmbito dessa morbidez algo naturalista, é um pouco surpreendente que, no próprio momento em que ela ganha um outro corolário antes da chegada ao castelo, no curso mesmo da árdua subida que conduz até ele - aliás, literalmente à sua sombra -, esse élan negativo também comporte um sutil mas significativo desvio. Galgando a pé as encostas do despenhadeiro, pai e filho chegam à casa de uma família de antigos servidores e

\footnotetext{
${ }^{26}$ Bernhard. Perturbação, p. 23.

27 Bernhard. Perturbação, p. 60.

${ }^{28}$ Cf. Bernhard. Perturbação, p. 64-75.
} 
agregados dos Saurau, e lá conhecemos o jovem Krainer, um rapaz aleijado, disforme e demente, de linguagem já quase inteiramente desarticulada, preso à cama - às vezes sob uma grade de ferro, para prevenir seus surtos de violência - e sob os cuidados da jovem irmã. Trata-se, agora, de um "louco de fato e totalmente desengonçado", cujo aspecto grotesco lhe empresta certa feição kafkiana. ${ }^{29}$ Fisicamente, pode-se dizer, trata-se do paciente mais monstruoso com que nos deparamos até agora; mas ao invés de conflitos psíquicos e morais, o que o episódio apresenta são os sintomas - cabais mas nisso mesmo algo 'inocentes' - de sua loucura, aliados, porém, a uma genialidade que, indissociável que seja da primeira, é de alguma forma maior que ela.

Violinista, conhecedor profundo e compositor de músicas eruditas antes do domínio da doença, e ainda agora executor de uma música "espantosa", o gênio de Krainer também se exprime na forma de uma autoconsciência orgulhosa mas irredutível à mera empáfia, e da qual o narrador vê um testemunho vivo nas gravuras de músicos famosos espalhadas nas paredes de seu quarto, sobre as quais ele escrevera frases que sintetizam sua visão a respeito deles:

Sobre a cabeça de Mozart escrevera "Muito grande!", e sobre a de Beethoven "Mais trágico do que eu!"; sobre a de Haydn, "Cabeça de porco" e sobre a de Gluck, "Você não me agrada". No rosto de Berlioz havia escrito "Espantoso" e no de Schubert "Feminóide". 30

Pra além de qualquer 'incorreção política', a força expressiva dessas tiradas se evidencia no interesse vivo que o narrador lhes dedica; o que por sua vez gera no próprio Krainer uma espécie de euforia, infantil mas ainda assim algo iluminada, como que reavivadora do antigo gênio, inclusive em sua agudez irônica (ele debocha do narrador quando vê que este não consegue ler algumas das inscrições).

Em suma, invertendo - ligeira ou consideravelmente - o etos ou élan narrativo predominante até então, Krainer é uma típica figura no molde romântico do grotescosublime ou grotesco sentimental que, do Quasímodo de Hugo às crianças-monstros de Kurt Vonnegut, povoam a chamada literatura ocidental. Veja-se ou não, aí, um resquício de ingenuidade - e seja qual for o valor (ou o estigma) que se atribui às noções de resquício (esse rastro estigmatizado enquanto anacronismo) e de ingenuidade -, o fato é que o episódio de Krainer é um índice seguro da irredutibilidade de Perturbação a sua negatividade

\footnotetext{
${ }^{29}$ Aliás, o personagem é comparado a um inseto gigantesco, dotado de cabeça pequena, abdômen enorme e manchas pelo corpo, lembrando muito, naturalmente, Gregor Samsa em A metamorfose. Sobre a influência de Kafka no primeiro romance de Bernhard, Gelo, cf. Long. The novels of Thomas Bernhard, p. 33-34.

${ }^{30}$ Bernhard. Perturbação, p. 82.
} 
entranhada. Não por acaso, é o episódio que fecha a primeira parte do romance, e também um lugar onde se entrevê um índice de positividade no protagonista da segunda, já que o mesmo príncipe que veremos externar seu ódio quase universal parece ter sido capaz, em mais de uma situação, de um zelo quase paternal - ambíguo como quase todo zelo desse tipo - pelo filho inútil dos vassalos. ${ }^{31}$ Aliás, Krainer é, o lado do príncipe - de quem, de fato, é vizinho no espaço diegético e na estrutura narrativa do livro -, provavelmente o personagem mais marcante de Perturbação: polo simbólico, portanto, de uma dialética que, simples que seja em seus termos, ganha força e complexidade únicas na prosa de Bernhard.

\section{Pais e filhos, príncipes e plebeus, alienados e alienistas: possessões de Sauran}

Poucas definições desse que é, sem dúvida, o grande personagem de Perturbação poderiam ser mais felizes que a de Bernardo Ajzenberg: "Expressão mais aguda desse caldeirão de perturbações é Saurau, personagem inesquecível, entre gênio e louco, um excêntrico senhor de castelo, tão rabugento quanto delirante". ${ }^{2}$ Talvez alguns desses termos soem um pouco amenos diante da verdadeira monstruosidade moral a que o príncipe às vezes se afigura; mas como essas vezes não são todas, e esse afigurar tem limites no 'real' da diegese, a concessão também vale: o excentrismo - como, aliás, já dissemos -, a rabugice e mesmo certo sentimentalismo são parte desse "personagem inesquecível, entre gênio e louco" (talvez fosse o caso, apenas, de inverter a ordem desses termos), que, entre outros massacres subjetivo-discursivos de pessoas, conceitos, instituições etc., acalanta e, ao mesmo tempo, se atormenta com verdadeiros sonhos de aniquilação.

Em certo sentido mais um entre outros (num "caldeirão", como escreve Ajzenberg), Saurau se eleva à condição de espelho do conjunto diegético por sua espécie de situação supertípica - digamos, por falar mais que todos entre outros falantes contumazes e tão parecidos -, mas também pelo gran de delírio de sua discursividade desenfreada; delírio e, portanto, riqueza: imagética e perceptiva: não raro, estamos diante, de fato, de um gênio, embora menos iluminado que mergulhado em trevas e sombras. Estas, aliás, agora muito mais psíquicas que 'objetivas', já que é um horizonte majestoso que se descortina do castelo. É claro que suas muralhas “interiores" e "exteriores” projetam suas sombras, como

\footnotetext{
${ }^{31}$ Fora o príncipe quem pagara a internação do jovem Krainer em Steinhof, "o maior e mais terrível dos manicômios europeus", e também quem financiara a estada e os passeios, que incluíram óperas e concertos, dele e sua irmã na capital do distrito; o que não impede que os irmãos Krainer tenham de habitar o mesmo quarto, "de maneira atroz, (...) por falta de espaço”. (Bernhard. Perturbação, p. 83-84.)

32 Ajzenberg. "Introdução", in: Bernhard. Perturbação, p. VII.
} 
seus cômodos abrigam suas trevas. Mas essas, provavelmente, são menores que a imensa sombra - do próprio castelo - sob a qual vivem permanentemente os Krainer, ou que a desolação ainda maior reinante no moinho dos Fochler; algo que é preciso sublinhar, não para condenar moralmente o príncipe como uma vítima de si mesmo, mas para explicitar a estrutura de poder determinante aí.

Não por acaso, também no discurso do príncipe, como sublinha ainda Ajzenberg, a questão da propriedade é um tema fundamental; aliás, nele mais que em todos, e nele se entranhando/desentranhando como em nenhum outro enquanto tensão ou agonística psíquica. O que se relaciona, sem dúvida, ao fato de a noção de propriedade não se ligar, aí, a um contexto estritamente capitalista, mas também à ideia de um pertencimento mútuo, ou seja, de uma fonte ou lugar de enraizamento e talvez subsunção de um si mesmo, um si próprio. Mas justamente nesse ponto há uma complexidade irredutível à mera oposição — do mundo feudal ou rural ao capitalista. A defesa dessa oposição, e de forma de forma um tanto mecanicista, no curso de uma leitura global e relativamente recente dos romances de Bernhard como é a de J. J. Lang ${ }^{33}$ parece sugerir que a complexidade dos ágons discursivos (sociais, psicológicos etc.) bernhardianos ainda solicita, a despeito dos avanços da crítica, análises mais sutis.

Sem dúvida há muito, em Saurau, da condição de um senhor feudal decaído. Não que seus negócios - a rigor, empreendimentos no mínimo semicapitalistas, de exploração silvícola e florestal - pareçam propriamente decadentes: apesar da catástrofe recente causada por uma inundação, e "a despeito de toda a evolução política" europeia e mundial, o príncipe se orgulha de ter "duplicado amplamente as posses herdadas de seu pai". Entretanto, o sentimento moral de que ele reveste seu isolamento reflete claramente a ideia de uma posição que já não é a de outrora. Saurau reclama, por exemplo, de ele mesmo ter tido, naquela manhã, de abrir a porta à saída de um candidato a um emprego em Hochgobernitz, "porque não há ninguém mais para abri-la, ninguém"; e, no entanto, logo adiante ele calcula "a receita de primavera das pedreiras" e se pergunta "se ainda são rentáveis essas jazidas de cascalho". ${ }^{35}$ Seja como for, sem dúvida a situação histórica e socialmente paradoxal do príncipe tem relação direta com sua discursividade rancorosa: os trabalhadores do castelo, o Estado austríaco, seu próprio filho - que ele descreve lendo textos revolucionários em Londres, ao invés de se preparar para assumir os negócios da

\footnotetext{
${ }^{33}$ Cf. Long. The novels of Thomas Bernhard, p. 46-49. Voltaremos adiante às posições de Long.

34 Bernhard. Perturbação, p. 135.

35 Bernhard. Perturbação, p. 104.
} 
família - e outros de seus alvos podem ser vistos como representantes do capitalismo em expansão, com suas contradições mesquinhas e seu etos rebaixado. $\mathrm{O}$ que não impede a mesquinharia de grassar no espírito do próprio príncipe, cujo primeiro grande tema, se podemos falar assim, é uma prova cabal disso.

A partir do momento em que encontram Saurau transitando entre as muralhas internas e externas do castelo, o médico e o narrador são como que tragados por sua profusão discursiva: sem mudar o ritmo de seus passos, aos quais os outros se forçam a se adaptar, o príncipe fala das entrevistas que realizara, naquela manhã, com três candidatos ao posto de administrador de Hochgobrnitz (o antigo, que lhe servira por décadas, morrera há dias num acidente). Zehetmayer, o primeiro desses candidatos, sobre o qual o príncipe discursa mais longamente, é descrito como uma "representação tópica das deficiências da pobreza, de decrepitude, da inferioridade e do cansaço mortal da existência humana"; alguém dotado "de uma mente submissa ao máximo, doentia, cheia dos imaginários fracassos mais doentios", ${ }^{36}$ e a quem Saurau não poupara da humilhação extrema, declarando-lhe sua absoluta incapacidade de assumir o posto pretendido e testando-o numa espécie de jogo behaviorista, no qual pronunciara palavras que acreditava serem quase insuportáveis para ele; por exemplo, a palavra toupeira, que, sempre conforme o príncipe, o atirara "instantaneamente" num "estado lastimável", pois "recordava-lhe a terra natal". ${ }^{37}$

Esses atos de linguagem atrozes, de cuja crueldade Saurau tem plena consciência "Os maiores crimes", declara, "são os de palavras que os dominantes cometem com os dominados" ${ }^{38}$-, deixam entrever o lugar fronteiriço entre a demência e o racionalismo exacerbado em que ele se move. Assim, a ânsia de distinção social contida nesses ritos imolatórios não disfarça seu teor ressentido e, afinal, autoexpositivo. Não apenas os parentes de Saurau, incluindo o próprio pai, tampouco podiam ouvir determinadas palavras - no caso do antigo príncipe, expressões como "chouriço, Auschwitz, SS, campanha da Crimeia ou politica realista" 39 -, como a atribuição a Zehetmayer das "mais catastróficas relações familiares" ou a conclusão de que ele, "sem dúvida, (...), é um louco", ${ }^{40}$ espelham claramente sua própria condição.

Ao mesmo tempo, o fato de o príncipe se apresentar como uma espécie de alienista, quando menos de analista da suposta loucura alheia, evidencia seu trânsito simbólico com o

\footnotetext{
${ }^{36}$ Bernhard. Perturbação, p. 89-90.

${ }^{37}$ Bernhard. Perturbação, p. 97-98; grifos do autor.

38 Bernhard. Perturbação, p. 92; grifos do autor.

${ }^{39}$ Bernhard. Perturbação, p. 97. A palavra "Alemanha" provavelmente substituiria todas essas expressões.

${ }^{40}$ Bernhard. Perturbação, p. 91 e 95, respectivamente; grifo do autor.
} 
médico. Este não parece propriamente um especialista em doenças mentais - aliás, o narrador comenta que ele só trata da insônia do príncipe, não de sua loucura ${ }^{41}-$, mas dá a entender várias vezes que lida com doentes incuráveis, justamente porque suas doenças (a única exceção parece ser o jovem Krainer) são menos de ordem fisiológica que psíquica e psicossocial. E nessa impotência mesmo se constata a imbricação do alienismo que constitui, por assim dizer, a lógica discursiva hegemônica em Perturbação - onde quase todos, zelosos da linguagem enquanto instrumento de apropriação, posse, do mundo ou seu sentido, expõem ou analisam demências ou semidemências, próprias ou alheias -, com a alienação prática, o alijamento da práxis humana em relação à realidade. Prática mas com bases profundamente psíquicas, ou melhor, psicossociais, como demonstram os elementos intimos dos discursos em jogo, onde o obscurantismo que reveste a consciência das misérias alheias expõe suas raízes niilistas.

Tema evidente desde o início do romance, o conflito entre pais e filhos é um dos elementos que vinculam de forma explícita os dois grandes eixos da narrativa, ou seja, os dramas familiares do narrador e do príncipe. Essa vinculação se dá, particularmente, pelo recurso a um outro motivo de possível inspiração kafkiana: o da carta ao pai. Precisamos, nesse ponto, voltar ao início do romance, mais exatamente a um momento posterior ao socorro infrutífero à mulher do taberneiro e ao almoço na casa do advogado. É após esses episódios que uma menção do médico a sua esposa falecida conduz o narrador a uma digressão sobre uma carta que havia escrito, interrogando o pai a respeito das “desafortunadas relações existentes entre nós três: entre mim e ele, entre ele e minha irmã e entre mim e minha irmã", ${ }^{42}$ Naturalmente, essa carta é, ela própria, um testemunho da corrosão dessas relações, inclusive na configuração psíquica e afetiva do narrador, e também de quão incompleta é sua consciência desse dado. Depois de afirmar ter tido, ao escrevê-la, “o maior cuidado de não magoar meu pai. De não magoar ninguém”, ele prossegue:

Redigira a carta de maneira desapaixonada e não me permitira nela nenhuma emoção, nem a mais insignificante, embora não faltassem os pontos culminantes que me propusera incluir, pontos que apareciam na carta em forma de perguntas diretas ou indiretas como, por exemplo, a quem cabia a culpa da mais recente tentativa de suicídio de minha irmã ou da morte prematura de minha mãe. ${ }^{43}$

Essas "perguntas" agressivamente retóricas permanecem irrespondidas pelo pai, mas é possível ler a via crucis emocional a que, supostamente por acaso, ele conduz o filho como

\footnotetext{
${ }^{41}$ Bernhard. Perturbação, p. 128.

${ }^{42}$ Bernhard. Perturbação, p. 17-18.

${ }^{43}$ Bernhard. Perturbação, p. 18.
} 
uma resposta indireta a elas, e cujo teor, explicitado, seria talvez semelhante à afirmação da esposa falecida de que seus filhos eram "mais filhos da paisagem que nos rodeava do que de nossos pais". ${ }^{44}$ Naturalmente, entre os elementos bumanos - e especulares - dessa "paisagem" destaca-se o príncipe, cujo filho, assim como o narrador, é estudante em outra cidade, no caso Londres. Descrevendo-o como um inútil que perde seu tempo lendo autores comunistas e anarquistas, ao invés de se preparar para assumir Hochgobernitz, Saurau ainda o acusa de não lhe escrever "nem uma carta sincera" 45 . Não obstante, é ele quem surge como o autor de um longo texto num sonho que o príncipe tivera na noite anterior, e de cujo conteúdo expresso Saurau afirma se lembrar inteiramente, recitando-o como se, de fato, o tivesse diante dos olhos: "vejo cada palavra que meu filho escreve". "Meu filho", afirma o príncipe, "destruirá Hochgobernitz quando o tiver em mãos", ${ }^{46}$ e o texto do sonho é, em síntese, uma assustadora ilustração dessa obsessão.

Nele, o jovem Saurau começa afirmando que não vencera seu pai "como se vence uma doença infecciosa", pois "essa doença é uma doença mortal - abaladora em sentido elementar - de que morrem todos, sem exceção". Segue-se a reiterada declaração de que, oito meses após o suicídio do pai - no espaço-tempo do sonho, é claro -, ele arruinara Hochgobernitz, referido, primeiro, como uma "empresa florescente" e, logo depois, como um "monstruoso anacronismo agrícola e florestal". Escrevendo como que em tempo real, no escritório do príncipe em Hochgobernitz - onde estuda textos revolucionários, mais exatamente a tese de que, ao contrário das revoluções burguesas, "a revolução proletária, que condena o assassinato, não necessita para os seus fins do terror" ${ }^{48}$-, o jovem Saurau vê alguém se aproximando, em aparições súbitas e fantasmais, pelas terras do castelo: trata-se de Moser, o secretário municipal, figura pela qual ele manifesta tanto ódio e repugnância quanto temor. É nos diálogos com Moser que todo o teor sinistro dos planos de aniquilação, aliás já em curso, do filho de Saurau vem à tona: indiferente aos insistentes pedidos do secretário para que deixe a população fazer a colheita da produção em vias de se perder, assim como aos seus discursos "a respeito da miséria do município, da miséria do povo, da miséria da humanidade, da pobreza, da comunidade, da comunidade popular", ${ }^{49}$ o jovem príncipe está disposto, de fato, a deixar que tudo apodreça à míngua, obstruindo o acesso às terras, derrubando árvores, cavando fossos nas trilhas etc.

\footnotetext{
${ }^{44}$ Bernhard. Perturbação, p. 17; grifos do autor.

45 Bernhard. Perturbação, p. 131.

${ }^{46}$ Bernhard. Perturbação, p. 135.

47 Bernhard. Perturbação, p. 135-136; grifo do autor.

48 Bernhard. Perturbação, p. 139; grifos do autor.

49 Bernhard. Perturbação, p. 147-148; grifo do autor.
} 
Não apenas isso, como o sentimento hostil com que envolve a população e, sobretudo, Moser enquanto seu representante ("A massa se tornou megalômana!"50), está em flagrante contradição com os supostos ideais revolucionários e contrários ao terror do jovem príncipe. Em sua leitura, Long reconhece esse dado e o interpreta - a nosso ver, corretamente - como um índice de que "a destrutividade evidenciada no sonho é atribuível somente ao próprio Saurau". ${ }^{51}$ De fato, basta lembrar que este, a certa altura, quando pensa "nos trabalhadores supérfluos das pedreiras (e das minas)", cogita "fechar as minas e fechar as pedreiras, fechar as minas e as pedreiras de uma só veq,", 52 para atestar isso. A explicação de Long para essa ânsia aniquiladora, entretanto, nos parece insuficiente: vinculando-a apenas ao "anacronismo" de Hochgobernitz afirmado no sonho, o crítico a toma como uma expressão da "consciência de uma interrupção fundamental da sucessão patrilinear e a concomitante transmissão de propriedade e título". A vontade de destruição de Hochgobernitz seria uma manifestação degradada dos "direitos de propriedade da aristocracia rural" em contexto adverso. ${ }^{53}$

Naturalmente, seria ingênuo recusar totalmente essa interpretação: já vimos a ânsia de distinção expressa pelo discurso do príncipe; mas reduzi-lo a isso significaria eliminar justamente sua complexidade e contraditoriedade irredutíveis, instaurados não apenas pelo fato de também do passado advir um peso negativo como, sobretudo, pelos movimentos de indistinção moral e fenomenológica produzidos nesse discurso. Mais que o topos da mudança, é o da continuidade fatalista que povoa as obsessões do príncipe. Após o episódio do sonho, ele continua a falar do filho, afirmando que este "poderia estudar em seu pai o que seria sua vida futura": seus objetivos, seus prazeres; o próprio "asco do pai diante do mundo" seria "o asco do filho". Mais ainda:

Em definitivo, disse, o filho morreria da mesma forma que seu pai, numa solidão em que só se podia entrar no próprio cérebro ou sair dele. Quando olhava para seu pai, disse, o filho via a miserabilidade do pai, do mesmo modo que o pai via continuamente a miserabilidade do filho. Pais e filho se viam continuamente em suas respectivas miserabilidades. "No entanto, o filho, afinal de contas, terá de ser muito mais horrível ainda do que o pai.",54

Em outro momento, essa disputa - expressão, podemos dizer, de algo como um complexo de Laio - é reaberta: "o pai vai sempre mais longe que o filho, ou, ao contrário, o

\footnotetext{
${ }^{50}$ Bernhard. Perturbação, p. 150.

${ }^{51}$ Long. The novels of Thomas Bernhard, p. 46. Traduzimos, o mais literalmente possível, as citações de Long.

52 Bernhard. Perturbação, p. 104; grifos do autor. Em outro momento, Saurau conta ter imaginado "que tinha mandado derrubar todas as árvores" de suas terras. Pouco adiante, delira sobre a "total extinção da humanidade" por asfixia. (Bernhard. Perturbação, p. 172 e 174, respectivamente.)

${ }^{53}$ Long. The novels of Thomas Bernhard, p. 46.

${ }^{54}$ Bernhard. Perturbação, p. 152-153; grifos do autor.
} 
filho vai sempre mais longe que o pai etc...". ${ }^{55} \mathrm{O}$ fato de o príncipe como que preconizar seu suicídio no sonho reflete a lembrança do suicídio (e da loucura) de seu pai; aliás, a lembrança de que "Quase todos os Saurau se suicidaram". ${ }^{56}$ Mais que a gradação das misérias, importa seu círculo vicioso, sua entranhada circularidade. Em outro lugar, o príncipe fala sobre "seus parentes", denominando-os "criaturas de raízes podres, inconcebíveis sem ele. Essa ideia, disse, fazia esquecer amiúde seu tédio e sentir um asco intranscendente [“stellenwertlosen Ekel" $\left.{ }^{57}\right]$ por seus corpos. 'Esses corpos saídos de mim', disse, 'engendrados por mim sem a menor afeição pela vida." ${ }^{58}$ A princípio, essa incômoda vinculação estaria ligada à procriação biológica, a filiação funcionando como índice de uma mesmidade cuja origem ou matriz, naturalmente, seria o pai. Saurau, entretanto, não se refere a seus filhos, mas, de fato, aos parentes ("Verwandten" "59), que incluem, no mínimo, as irmãs que moram com ele no castelo. Em outro momento ele se refere explicitamente a "minhas irmãs e minhas filhas" para dizer que "os vejo a todos, também meu filho (...); vejo-os a todos existindo por mim, e tomo consciência de uma situação monstruosa que é, provavelmente, o próprio assombro: sou sen pai? ${ }^{60}$ Seria possível inferir um deslizamento, não registrado sintaticamente (em consonância com a 'oralidade' do discurso), dos objetos referenciais do príncipe, mas como ele ainda usará, na sequência, a expressão "vejo a todos", o deslizamento mais provável é o do topos biológico para o da paternidade em um sentido mais amplo, deformador da idéia de herança biológica e social em hegemonia 'natural'metafísica. Isso nos parece um índice importante de que as ideias de herança e propriedade constituem, em sua articulação indissociável, elementos subsunsores mais fortes no discurso de Saurau, e portanto em Perturbação, do que o conflito entre tradição e modernidade.

\footnotetext{
55 Bernhard. Perturbação, p. 148.

${ }^{56}$ Bernhard. Perturbação, p. 178.

57 Bernhard. Verstörung, p. 133. Apesar de muito sugestiva, a ponto de não resistirmos a jogar com ela em nosso título, a expressão "intranscendente" é no mínimo problemática como tradução de "stellenwertlosen". Em conversa particular conosco, o tradutor George Bernard Sperber caracterizou esse vocábulo como "uma daquelas palavras compostas que fazem a felicidade dos alemães e a infelicidade dos tradutores". Sendo, entretanto, Wert "valor" e Stelle "local”, "posição", "localização", Sperber considera a solução de Welper e Melo "uma boa sacada". Uma tradução de "stellenwertlosen Ekel" mais próxima do literal mas literariamente inviável seria, segundo Sperber, "nojo carente de posição relativa"; e, de fato, "asco intranscendente" guarda a ideia de uma repulsa sem termo de comparação, na qual acentua (ou, talvez, à qual acrescenta) a ideia de um entranhamento irrecorrível no âmago de quem sente.

58 Bernhard. Perturbação, p. 153.

${ }^{59}$ Bernhard. Verstörung, p. 133.

${ }^{60}$ Bernhard. Perturbação, p. 131.
} 
Não por acaso, imediatamente antes dessa passagem o príncipe dissertava sobre sua tentativa de "aclarar, clarificar e aclarar novamente o conceito de natureza", sendo que tal conceito, para ele, comporta uma espécie de subsunção mútua entre a consciência, a existência social e as relações de poder humanas e a natureza enquanto 'espaço natural' e fenômeno biológico: "Quanto mais se distancia do conceito convencional de natureza, mais belo, poderoso - eu diria poético - é". ${ }^{2}$ Daí, por exemplo, a ideia de que o "cultivo florestal" é não só "uma ciência econômica" como "uma ciência natural pura", afirmação contraposta à de que as desapropriações de terra promovidas pelo Estado "Arruínam a natureza", e de que "o Estado está bichado", esta revelando seu teor quase literal quando se percebe o quanto Saurau se preocupa com "o problema do anticorpo na natureza" ${ }^{63}$. O preço disso tudo é uma espécie de autofagia filosófica, a elisão prévia da natureza enquanto realidade transcendente às contradições humanas. A certa altura, o príncipe pede que o médico e o narrador observem os homens que trabalham na ponte do castelo:

“A todos esses sujeitos que estão aí tremelicando de frio eu tenho de pagar, tenho de pagar a todos esses sujeitos tremelicantes. Pago a esses homens por um vício da natureza, por um vício da natureza pago a todos esses homens inúteis". ${ }^{64}$

O próprio caos reinante no mundo - senão sua propensão niilista - se torna um processo natural: "O príncipe disse: 'Tenho sempre a impressão de que seria natural que a qualquer momento o mundo se desintegrasse. Ou é talvez a natureza que deve aniquilarse?', perguntou. 'Esse processo provém sempre de dentro e atua para fora. (...)"”. ${ }^{65}$

Daí a tortuosa dialética de 'intrinsiquismo' e 'extrinsiquismo' - ou seja, de complexas e não raro incompatíveis reduções à interioridade e à exterioridade -, visível desde a narração em abismo, passando pelos limites imprecisos de Hochgobernitz (castelo, feudo, floresta, espaço psíquico que se projeta sobre outros), com suas muralhas "interiores" e “exteriores", e manifestando-se sobretudo na fenomenologia mental do príncipe, com sua

\footnotetext{
61 Bernhard. Perturbação, p. 131.

62 Bernhard. Perturbação, p. 112. Tal "conceito convencional" parece remeter ao "fenômeno da natureza" (o castanheiro em flor) que, como vimos, o médico quer mostrar ao filho no passeio matinal para o qual o convida no início. As perturbações em jogo no romance comportam, portanto, essa dimensão 'fillosófica': a ingenuidade 'naturalista' da concepção de natureza do médico é problematizada por Saurau, embora essa problematização já estivesse latente no "fenômeno" a que o primeiro se refere, já que se trata de um fenômeno atípico.

${ }^{63}$ Bernhard. Perturbação, p. 110-111 e 129; grifos do autor.

${ }^{64}$ Bernhard. Perturbação, p. 133; grifo nosso. No outro lado dessa mesma moeda, diz o príncipe que em Hochgobernitz “imperam (...) leis naturais próprias, as do Saurau”. (Bernhard. Perturbação, p. 103.)

65 Bernhard. Perturbação, p. 132; grifo nosso. Em pelo menos um momento, quando fala sobre o que espera seu filho em Hochgobernitz, Saurau parece manifestar consciência do caráter patológico de sua "filosofia natural": "Demência que traspassa o indivíduo como demência do mundo, da natureza". (Bernhard. Perturbação, p. 176.)
} 
lógica ao mesmo tempo tautológica e contraditória, oscilando entre a recusa e a afirmação fatalista de um pertencimento degradado. Quando, por exemplo, ele fala sobre os ruídos que assolam permanentemente seu cérebro, reclama que nenhum outro cérebro "se deu conta desses ruídos e nunca se dará conta deles"; e prossegue:

"O fato de ser assim não me abala, mas que seja só eu quem - que meu cérebro seja o único que - tenha que registrar o que, por essa causa, se me afigura horroroso e mortal. O que me rodeia - e sempre excluo de mim, de meu cérebro, por assim dizer, de um Hochgobernitz intelectual, de meu entorno imediato e mais imediato, o total, o mundo inteiro etc... no qual, em todo caso", disse o príncipe Saurau, "cabe toda a humanidade - é de uma incapacidade de percepção, de registro, de absorção... que quase paralisa a vida. Este fato é, para mim, mortal, isto é um fato mortal para mim: que nesse fato eu esteja sozinho, que esteja sozinho nesse fato. Esse gigantesco rio de lama!" 66

O que Saurau diz excluir de si é tudo aquilo, ou melhor, aqueles que não são capazes de perceber, registrar e absorver o mesmo "gigantesco rio de lama" - o "total, o mundo inteiro", "a humanidade toda" etc. - repudiado por ele, mas que ele mesmo percebe, registra etc. Enfim, aquilo a que ele veda a entrada em seu "Hochgobernitz intelectual" é aquilo que o toma, exatamente como o jovem príncipe declara no sonho que Moser "Não conhece Gobernitz por dentro, (...), mas não seria Moser (...) se não conhecesse o interior do castelo". ${ }^{67}$ Aliás, é na figura de Moser que tudo isso ganha sua imagem mais sinistra, como que coroando, na forma de uma espécie de alteridade incompleta e negativa, a "filosofia"/metafísica da natureza de Saurau. Definindo-o como "um típico representante da ruindade e da baixeza do Estado”, o príncipe diz que o administrador municipal "encarna algo que ninguém deveria ignorar: que o homem é baixo e ruim, e que quem o engendra, pelo fato de engendrá-lo, é ainda mais baixo e vil. Moser desqualifica o mundo e seu Criador" ${ }^{68}$ Não é difícil perceber aí, nessa desqualificação retroativa, um reflexo da problemática de Saurau com seu filho, por meio de um processo significacional que não é apenas de construção simbólica, mas também de redução de uma alteridade, já que Moser figura 'real' ou não na diegese do romance - se configura sociológica e psicologicamente como tal.

\footnotetext{
${ }^{66}$ Bernhard. Perturbação, p. 133; grifo do autor. A expressão "rio de lama" remete sutilmente à lembrança de uma enchente que, pouco tempo antes, devastara as terras de Saurau, e da qual ele falara, páginas antes, valendo-se de tal expressão. Maior que a enchente, ele ainda havia dito, fora a "devastação inimaginável” causada pelos tais ruídos na sua cabeça. (Bernhard. Perturbação, p. 119; grifos do autor.) Além disso, outro transbordamento do mesmo rio se liga à lembrança do suicídio do velho príncipe, que havia se matado enquanto Saurau estava "lá embaixo, no Ache, vendo baixar a enchente". (Bernhard. Perturbação, p. 181.) Cumpre notar, também, que esse rio é o mesmo a cujas margens se dá o "fenômeno a natureza" ao qual o médico se refere no início.

${ }^{67}$ Bernhard. Perturbação, p. 144-145.

68 Bernhard. Perturbação, p. 140; grifos do autor. A manutenção da maiúscula em "Criador" - "Schöpfer", no original (Bernhard. Verstörung, p. 122) - é, naturalmente, um caso de decisão crítica do tradutor, mas a opção pela minúscula não alteraria significativamente a situação.
} 
E não é difícil interpretar tudo isso em termos de uma estrutura e/ou mentalidade feudal decadente: o próprio Saurau declara acreditar "cada vez mais que sou tudo porque na realidade não sou mais nada". ${ }^{69}$ Mas insistir nesse conflito - nesse dado motivador do romance - como um elemento subsunsor de sua gama de conflitos implica em tolher seu horizonte significacional. Para além da oposição feudalismo/capitalismo, o sentimento de propriedade - social e psíquica, identitária - de Saurau abarca de forma muito mais efetiva esses conflitos. Ele se reflete, por exemplo, na relação entre o médico e o narrador, marcada pela mesma relação de exigência de aceitação de um legado existencial - e, no caso do príncipe, material - que se institui, certamente com muito mais força, na relação do príncipe com seu filho: na longa fala em que, como que ecoando a da Sra. Ebenhön, o médico disserta sobre sua própria família, ele expõe suas convicções e esperanças a respeito do filho, sem que este perceba exatamente que está sendo sutil e, por isso mesmo, levianamente orientado. ${ }^{70}$

Ao mesmo tempo, a espécie de contágio comunicativo ou empático entre a paciente e o médico, confinada aos limites do individualismo e incompleta que seja (antes do fim da fala dele ela cai no sono), alerta para a impossibilidade de aplicar ao conjunto do romance uma afirmação como a de Ajzenberg, no rastro de Aldo Gargani, de que "o mote permanente do discurso de Saurau é a impossibilidade de se comunicar com os outros" ${ }^{\text {"71 }}$, ou pelo menos de reduzir a isso sua temática. Pelo contrário: é sobretudo da comunicação das obsessões que Perturbação trata. E também nisso, ou seja, em suas condições assemelhadas de fontes de heranças obsessivas, o trânsito simbólico entre o médico e Saurau é importante: ao final do romance, quando tenta se dedicar à irmã em seu último dia de visita à família, o narrador - filho do primeiro e, agora, como que também do segundo - não consegue se livrar das obsessões deste. O confinamento à individualidade não se dá à margem, mas na saturação das propriedades, dos legados materiais, simbólicos e psíquicos.

Perturbação pode ser lido como uma dramatização - um drama-romance de uma tensão quase perene, cuja ausência de clímax o reforça enquanto tragédia latente, ou melhor, tragédia em curso - do topos da propriedade (ou, em vocabulário menos técnico, uma denúncia da propriedade, ou da propriedade-identidade) enquanto lugar de determinação das

\footnotetext{
${ }^{69}$ Bernhard. Perturbação, p. 134.

${ }^{70}$ Cf. Bernhard. Perturbação, p. 36-40. Tudo isso, cumpre notar, confere a essas figuras paternas a força das injunções espectrais trabalhadas por Jacques Derrida em Espectros de Marx. Apesar dessa referência en passan, os motivos derridianos das demandas e da espectralidade - ou melhor, da espectralidade como índice de demandas exigentes, demandas-injunçoes - é fundamental na leitura aqui empreendida; muito embora deixemos de lado, aqui, as manifestações propriamente espectrais do romance, que exigiriam tratamento à parte.

${ }^{71}$ Ajzenberg. "Introdução", in: Bernhard. Perturbação, p. IX.
} 
relações - e agonísticas - sociais e psíquicas. É o sentimento de propriedade que, não apenas na fala de Saurau, mas como que se alavancando nela, se projeta sobre tudo e em tudo se espraia no romance, na duplicidade de apossamentos que são também possessões, reduções de outros a um si mesmo, ou melhor, a si mesmos que se veem simultaneamente tomados por eles. O fato de o príncipe reconhecer "um tremendo distanciamento e alienação" 72 em seus parentes não o purga de sua própria alienação social, mas é um indício de que a mental - sua loucura - é parte de um ágon não de todo inconsciente com ela. Afinal, é em seu virtuosismo simultaneamente auto e alterfágico que Saurau explicita a força do que se pode denominar, em oposição à sua própria afirmação do mundo como "uma escola da morte", lugar de um contínuo "aprender a morrer e aprender a estar morto", 73 o apego à vida, afinal transbordante, em seu discurso e na prosa de Bernhard. As temidas e recusadas alteridades abissais, de que o miserável príncipe não pode se livrar - é ele quem retoma, no fio de seu discurso, a citação de $\mathrm{Pascal}^{74}$-, são também seu principal alimento. Ao mesmo tempo, querer fazer delas de alguma forma seus herdeiros - quando menos de seus rancores - traduz também, decerto que paradoxalmente, a ânsia de uma saída de si, um livrar-se de si. Como os próprios sonhos de aniquilação do príncipe são também, evidentemente, sonhos de libertação, de transcendência de tudo o que constitui e determina seu pesadelo vivo: não apenas ou propriamente Hochgobernitz, mas um complexo carcerário histórico, social, espiritual, identitário, utilitário - muito maior.

Afinal, não é o fato de considerar Hochgobernitz "uma prisão perpétua" que impede Saurau de declarar: "Hochgobernitz eu amo",75. Assim como sua projeção das mazelas históricas e angústias psicológicas sobre a natureza não o impede de reconhecer, em dada alteridade (Henzig, o candidato a administrador afinal escolhido), "os bosques gigantescos que há entre o Innviertel e as planícies da Baviera ou a infinitude dos bosques eslovenos" e, mais ainda, "a calma infinita" da natureza ${ }^{76}$. Como o amor não menos vivo pelas palavras - as mesmas que obsedam seus personagens, e outras, ainda - não deixa de exalar desse romance. Por isso sua representação da linguagem como delírio de apropriação do mundo não se confunde com a redução da linguagem - ou dos lugares, "a paisagem" - a uma negatividade existencial, naturalista ou metafísica: é no ágon entre tal delírio e outras

\footnotetext{
${ }^{72}$ Bernhard. Perturbação, p. 134; grifos do autor.

${ }^{73}$ Bernhard. Perturbação, p. 157-158.

${ }^{74}$ Bernhard. Perturbação, p. 188.

${ }^{75}$ Bernhard. Perturbação, p. 187.

${ }^{76}$ Bernhard. Perturbação, p. 102; grifos do autor. Tais "infinitude dos bosques" e "calma infinita" - no original, respectivamente, "Waldunendlichkeit" e "unendliche Ruhe" (Bernhard. Verstörung, p. 90) - invertem positivamente, a nosso ver num jogo proposital, os "abismos infinitos" ("unendlichen Räume”) que aparecem na epígrafe e, como acabamos de indicar, no próprio discurso do príncipe.
} 
práticas, conexas, e os mistérios que sempre emanam dos abismos - sobretudo os humanos - que toda a perturbação que vemos em curso revela em seu 'fundo' um indomável entusiasmo. A riqueza e a complexidade da representação da vida em Perturbação são frutos desse ágon e desse entusiasmo.

\section{REFERÊNCIAS}

Ajzenberg, Bernardo. "Uma desafiadora aventura mental". In: Bernhard, Thomas. Perturbação. Trad. de H. P. Welter e J. L. de Melo. Rio de Janeiro: Rocco, 1999, p. VII-X.

Bernhard, Thomas. Perturbação. Trad. de H. P. Welter e J. L. de Melo. Rio de Janeiro: Rocco, 1999.

Bernhard, Thomas. Verstörung. Frankfurt: Suhrkamp Taschenbuch, 1990.

Derrida, Jacques. Espectros de Marx. Trad. de Anamaria Skinner. Rio de Janeiro: Relume Dumará, 1994.

Long, Jonathan J. The novels of Thomas Bernhard: form and its function. Rochester, New York: Camden House, 2001.

Pinto, Rodrigo Hayasi. A noção de perspectivismo na filosofia de Blaise Pascal. Tese de Doutorado. São Carlos: Universidade Federal de São Carlos, 2006. 